\title{
Impact of short-term antiretroviral therapy (START) on some fibrinolytic markers in HIV-infected Nigerian adults: preliminary findings from the START study
}

\author{
This article was published in the following Dove Press journal: \\ HIVIAIDS - Research and Palliative Care \\ 9 July 2012 \\ Number of times this article has been viewed
}

\section{Zaccheaus A Jeremiah' \\ Yetunde Obazee ${ }^{2}$ Godwin R Okogun ${ }^{3}$ \\ Teddy C Adias ${ }^{4}$ \\ Osaro Mgbere ${ }^{5,6}$ \\ Ekere J Essien ${ }^{6}$}

'Hematology and Blood Transfusion Science Unit, Department of Medical Laboratory Sciences, College of Health Sciences, Niger Delta University, Wilberforce Island, Bayelsa State, ${ }^{2}$ General Hospital, Maitama District, Abuja, Federal Capital Territory, ${ }^{3}$ Department of Medical Laboratory Science, Ambrose Ali University, Ekpoma, Edo State, Nigeria; ${ }^{4}$ College of Health Technology, Bayelsa State, Nigeria; ${ }^{5}$ Houston Department of Health and Human Services, ${ }^{6}$ Institute of Community Health, University of Houston, Texas Medical Center, Houston, TX, USA

\footnotetext{
Correspondence: Zaccheaus A Jeremiah Hematology and Blood Transfusion Science Unit, Department of Medical Laboratory Sciences, College of Health Sciences, Niger Delta University, Wilberforce Island, Bayelsa State, Nigeria

Tel +234 (803) 4045636

Email zacjerry@yahoo.com
}

Background: Derangement in fibrinolytic markers can result in thrombosis and cardiovascular problems. Antiretroviral therapy (ART) has been reported to affect the levels of these markers. It is unclear how long a patient can be exposed to ART before the effect of the drugs on the fibrinolytic markers becomes noticeable; this short-term antiretroviral therapy (START) study aimed to answer this question.

Methods: Twenty human immunodeficiency virus (HIV)-positive subjects on ART and 20 controls (non-ART) were progressively monitored for three months. CD4 T-cell count was determined while D-dimer, t-PA, and PAI-1 parameters were determined.

Results: CD4 T-cell count increased from $192 \mu \mathrm{L} / \mathrm{mL}$ at baseline to $323 \mu \mathrm{L} / \mathrm{mL}$ at month 3 among patients on ART. D-dimer concentrations decreased from $301.0 \mu \mathrm{L} / \mathrm{mL}$ at baseline to $172.0 \mu \mathrm{L} / \mathrm{mL}$ at month 2 , then increased to $226.0 \mu \mathrm{L} / \mathrm{mL}$ at the end of the third month. The median baseline concentration of PAI- 1 at the beginning of therapy was $14.0 \mu \mathrm{g} / \mathrm{mL}$, which increased progressively to $18.2 \mu \mathrm{g} / \mathrm{mL}$ at the end of the third month. The baseline concentration of t-PA at the beginning of therapy was $5.15 \mu \mathrm{g} / \mathrm{mL}$. This progressively declined to $1.10 \mu \mathrm{g} / \mathrm{mL}$ at the end of the first month and reached $1.45 \mu \mathrm{g} / \mathrm{mL}$ and $1.5 \mu \mathrm{g} / \mathrm{mL}$ at the end of the second and third months, respectively. D-dimer was positively and significantly correlated with CD4 cell counts in both AIDs-associated retrovirus (ARV) and non-ARV patients $(r=-0.304, P<0.01$ vs $r=-0.477, P<0.001)$. t-PA was negatively correlated with CD4 T-lymphocytes in those undergoing ART $(r=-0.294, P<0.01)$.

Conclusion: A progressive increase in PAI-1 and steady decline in t-PA concentrations within 3 months of commencement of ART could predispose patients to thrombotic disorders earlier than is expected. Pre-thrombotic assessment during therapy is therefore advocated.

Keywords: fibrinolytic markers, D-dimer, t-PA, PAI-1, START study

\section{Introduction}

The main purpose of antiretroviral therapy (ART) is to improve the prognosis of patients infected with human immunodeficiency virus (HIV) by decreasing the incidence of opportunistic infection and subsequent hospitalization and mortality. ${ }^{1}$ However, several studies have suggested that highly active antiretroviral therapy (HAART) results in a higher incidence of cardiovascular events. ${ }^{2,3}$

In the normal fibrinolytic system, thrombin converts fibrinogen to active fibrin. Plasmin then degrades the cross-linked fibrin into soluble degradation products by the tissue type (t-PA) and the urokinase-type plasminogen. It is the t-PA that is mainly responsible for the dissolution of fibrin formed in the circulation, ${ }^{4}$ and the normal process 
of fibrinolysis can be inhibited either by antagonizing plasmin through alpha-2-antiplasmin or by specific plasminogen activators (PAI) of which there are three types. PAI type 1 (PAI-1), which is synthesized in endothelial cells, adipocytes, and the liver, is physiologically the most important. ${ }^{4}$ Elevated plasma t-PA indicates inhibited endogenous fibrinolysis, and occurs when free t-PA released into the blood from endothelial cells forms a complex with circulating PAI-1. As a result, assays of t-PA antigen predominantly measure inactive t-PA/PAI-1 complexes. Concentration of the t-PA/ PAI-1 complex levels in plasma correlate strongly with levels of t-PA antigen and PAI-1 activity. ${ }^{5,6}$ There is evidence that elevated t-PA levels predict cardiovascular disease in apparently healthy individuals, ${ }^{7}$ and this has been reported to account for more than $20 \%$ of deaths in some studies of HIV-infected patients. ${ }^{8}$

To date, most studies of the effects of ART involve monitoring HIV-infected patients undergoing therapy for 6 months to 1 year, the general assumption being that the effects of ART on hematological and hemostatic parameters will be noticed after a prolonged period. The null hypothesis for the current study is that short-term therapy of HIV-infected patients will have no significant effect on fibrinolytic markers. The main objective of a START study is to find out whether changes other than hematological changes occur during short-term ART, which could form the basis of further monitoring and improvement in the management of HIV-infected patients. This START study aimed to determine the values of fibrinolytic parameters within the first 3 months of ART, determine the period before changes in these parameters are noticeable, and assess the dangers associated with late commencement or noncommencement of ART.

\section{Materials and methods Study participants}

The study participants comprised cohorts of 20 patients aged from 18 to 60 years who were receiving health care at the Asokoro District Hospital in the Federal Capital Territory, Abuja, Nigeria. The Asokoro District Hospital has a center where special care such as voluntary counseling and testing, ART, and follow-up are provided. A total of 40 participants were enrolled in the START study with each group consisting of 20 participants. The inclusion criteria for patients were as follows:

- Group 1: Aged 18-60 years; must have tested positive for HIV and not previously been on any antiretroviral drug, and must not present any symptom suggestive of a systemic disease.
- Group 2: Aged 18-60 years; must have tested positive for HIV but not be willing to commence ART for at least 3 months, and must not present with any symptoms suggestive of a systemic disease.

Participants with sickle cell disease or hepatitis, who were pregnant, or who were taking oral contraceptives were excluded from the study.

The START study received institutional ethical approval from the management of the Asokoro General Hospital. Patients signed a written informed consent form, and were enrolled into the study before blood samples were collected.

\section{Experimental design}

A repeated measures design comprising an experimental or treatment group and one control group was adopted for this study. This design allowed for a longitudinal study of individual subjects in which fibrinolytic parameters were measured multiple times under different conditions, thereby monitoring trends during the 3 -month study period. The experimental group comprised HIV-positive individuals (ART naïve subjects) who registered for ART (Group 1), and the positive control group which consisted of HIV positive individuals but who were not on ART (Group 2).

\section{Analytical procedures}

\section{Sample collection}

A total of $7 \mathrm{~mL}$ of blood was collected by clean venous puncture from participants, with $4.5 \mathrm{~mL}$ blood delivered into a bottle containing $0.5 \mathrm{~mL}$ sodium citrate and $2.5 \mathrm{~mL}$ into a bottle containing EDTA anticoagulant.

\section{CD4 T cell count (Partec flow cytometry counter)}

Principle and sample preparation: When red blood cells are mixed with CD4 monoclonal antibody in the presence of phycoerythrin, the cells are coated in phycoerythrin. When passed through the measuring area, cells or particles are illuminated by fluorescent light and are then measured and analyzed. Twenty microliters of well mixed whole blood (with EDTA added as an anticoagulant) was pipetted into a Partec test tube. Twenty microliters of CD4 mAb PE was then added, mixed gently, and this was then incubated for 15 minutes at room temperature, protected from light, and $800 \mu \mathrm{L}$ of no lyse buffer was then added and mixed gently. CD4-PE fluorescence was analyzed on a Partec flow cytometer with an excitation light source with a wavelength of $488 \mathrm{~nm}$. Following this, $840 \mu \mathrm{L}$ of the prepared blood sample was transferred to the cytometer for 
CD4 determination. The results were displayed as CD4 cells per $\mu \mathrm{L}$ whole blood.

\section{D-dimer (Technozym ${ }^{\circledR}$ D-Dimer ELISA Kit, Lot \# RH02BOO)}

D-dimer concentrations in plasma were determined using ELISA kits (Technozym ${ }^{\circledR}$ D-Dimer, Lot \# RH02B00) purchased from Technoclone (Vienna, Austria). Citrated plasma and all required components in the kit were brought to room temperature. One hundred microliters of calibrators, control plasmas, and test samples was pipetted into test wells, covered with film, and incubated in a hot air oven at $37^{\circ} \mathrm{C}$ for 60 minutes. The test wells were then washed three times with $200 \mu \mathrm{L}$ washing buffer, using an automated ELISA washer. One hundred microliters of conjugate working solution was pipetted into wells, covered with strips of film, and then incubated at $37^{\circ} \mathrm{C}$ for 60 minutes. Following this, the wells were washed three times with $200 \mu \mathrm{L}$ of washing buffer. One hundred microliters of substrate solution was then pipetted into test wells, covered test strip with film, and then incubated at room temperature for 10 minutes. One hundred microliters of stopping solution was then added into wells, these were shaken for 10 seconds, and measured within 10 minutes using an ELISA reader at a wavelength of $450 \mathrm{~nm}$. Concentrations of test samples were read off from the calibration curve and also checked with the controls.

\section{Tissue plasminogen activator $\left(\right.$ Technozym $^{\circledR}$ t-PA antigen ELISA, Lot \# RC05BOO)}

Citrated plasma and all required components in the kit were brought to room temperature. Twenty-five microliters of calibrators, control plasmas, and test samples were pipetted into test wells, $75 \mu \mathrm{L}$ of incubation buffer was then added, and wells were covered test strips with film and incubated in a hot air oven at $37^{\circ} \mathrm{C}$ for 60 minutes. Wells were emptied thoroughly, $100 \mu \mathrm{L}$ of conjugate working solution was pipetted into wells, and these were covered with film. The test wells were incubated at $37^{\circ} \mathrm{C}$ for 60 minutes and washed three times with $200 \mu \mathrm{L}$ of washing buffer. One hundred $\mu \mathrm{L}$ of substrate solution was then pipetted into test wells, covered test strip with film, and then incubated at room temperature $\left(20^{\circ} \mathrm{C}-25^{\circ} \mathrm{C}\right)$ for 20 minutes. One hundred $\mu \mathrm{L}$ of stopping solution was pipetted into wells; these were shaken for 10 seconds, and then measured using an ELISA reader at a wavelength of $450 \mathrm{~nm}$ within 10 minutes. Concentrations of test samples were read off from the calibration curve and also cross checked with the controls.

\section{Plasminogen activator inhibitor-I Technozym $^{\circledR}$} PAI-I Antigen ELISA, Lot \# RD I IBOO)

Citrated plasma and all required components in the kit were brought to room temperature. Twenty-five $\mu \mathrm{L}$ of calibrators, control plasmas, and test samples was pipetted into test wells, $75 \mu \mathrm{L}$ of incubation buffer was added, and then covered test strips with film and incubated in hot air oven at $37^{\circ} \mathrm{C}$ for 60 minutes. Wells were emptied, and $100 \mu \mathrm{L}$ of conjugate working solution was pipetted into wells which were then covered with film. The wells were further incubated at $37^{\circ} \mathrm{C}$ for 60 minutes and washed three times with $200 \mu 1$ washing buffer. One hundred $\mu \mathrm{L}$ of substrate solution was then pipetted into test wells, covered test strip with film and then incubated at room temperature $\left(20^{\circ} \mathrm{C}-25^{\circ} \mathrm{C}\right)$ for 20 minutes. One hundred $\mu \mathrm{L}$ of stopping solution was pipetted into wells, shaken for 10 seconds, and measured using an ELISA reader at a wavelength of $450 \mathrm{~nm}$ within 10 minutes. Concentrations of the test samples were read off from the calibration curve, and checked with the controls.

\section{Statistical analysis}

Data obtained from the study were subjected to descriptive statistics (such as calculation of means and standard deviations) to allow a general evaluation of all study variables. Inferential analyses were conducted using repeated measures analysis of covariance (ANCOVA) with between-subject variable conditions (experimental vs control), demographic characteristics, and therapy duration. The measured parameter values within each group at baseline were used as covariates, while the interaction effect of associated independent factors was included in the analytical models of all study outcomes. Analysis to determine the existence or otherwise of relationships within and between fibrinolytic parameters over the START study duration was carried out by conducting correlation analyses. All analyses were performed using SPSS software version 16.0 (SPSS Inc, Chicago, IL).

\section{Results}

The distribution of the study population by sociodemographic characteristics is presented in Table 1 . There were more males $(60 \%)$ than females $(40 \%)$, and $60 \%$ of the study participants were between 26 and 36 years of age. The average age was $34.3 \pm 5.36$ years. Participants who worked in the field of business represented $57.6 \%$ of the study population.

Table 2 shows the overall correlation between measured parameters by ART. D-dimer was positively and significantly correlated with CD4 $\mathrm{T}$ lymphocyte counts in both 
Table I Distribution of study population by sociodemographic characteristics

\begin{tabular}{lll}
\hline Characteristics & N & $\%$ \\
\hline Therapy & & \\
$\quad$ ARV & 20 & 50.0 \\
Non-ARV & 20 & 50.0 \\
Sex & & \\
$\quad$ Male & 24 & 60.0 \\
Female & 16 & 40.0 \\
Age group (years) & & \\
$\quad$ 25 & 3 & 7.5 \\
$26-36$ & 24 & 60.0 \\
$\geq 37$ & 13 & 32.5 \\
$\quad$ Average age (SD) $=34.33$ years (5.36 years) & & \\
Occupation & & \\
$\quad$ Business & 23 & 57.6 \\
Civil servant & 9 & 22.5 \\
Military & 3 & 7.5 \\
Housewife & 2 & 5.0 \\
$\quad$ Students & 3 & 7.5 \\
Total & 40 & 100 \\
\hline Abbreviation: ARV, acquir
\end{tabular}

Abbreviations: ARV, acquired immunodeficiency syndrome-associated retrovirus; SD, standard definition.

AIDs-associated retrovirus (ARV) and non-ARV patients ( $r=-0.304, P<0.01$ vs $r=-0.477, P<0.001)$. t-PA was negatively and significantly correlated with CD4 T lymphocytes only in those undergoing ART $(r=-0.294, P<0.01)$. Age was positively correlated with CD4 T lymphocytes and negatively correlated with D-dimer $(r=0.244, P<0.001$ vs $r=-0.446, P<0.001)$.

PAI-1 was not significantly correlated with any of the parameters among patients undergoing ART but was weakly correlated with D-dimer among patients not receiving ART ( $r=0.261, P<0.05)$. When different durations of therapy were examined, PAI-1 correlated negatively and significantly with t-PA at baseline and at month $1(r=-0.543, P<0.01)$, while PAI-1 correlated positively and strongly with D-dimer values at month $2(r=0.550, P<0.01)$. At month $3, \mathrm{CD} 4$ correlated negatively and significantly with D-dimer and t-PA

Table 2 overall correlations between measured parameters by antiretroviral therapy

\begin{tabular}{llllll}
\hline Parameter & Age & CD4 & D-dimer & PAI-I & t-PA \\
\hline Age & & 0.017 & $-0.228^{*}$ & 0.062 & -0.115 \\
CD4 & $0.274 * *$ & & $-0.477^{* * *}$ & 0.102 & -0.163 \\
D-dimer & $-0.466 * * *$ & $-0.304 * *$ & & $0.26 I^{*}$ & 0.071 \\
PAl-I & -0.115 & 0.159 & 0.164 & & -0.177 \\
t-PA & 0.036 & $-0.294^{* *}$ & 0.046 & -0.079 & \\
\hline
\end{tabular}

Notes: Correlation values below the diagonal are for HIV patients on ARV therapy, while correlation values above diagonal are for HIV patients on no $A R V$ therapy $(\mathrm{N}=80)$. Significance levels: $* P<0.05$; $* * P<0.01$; $* * * P<0.001$.

Abbreviations: ARV, acquired immunodeficiency syndrome-associated retrovirus; HIV, human immunodeficiency virus; t-PA, tissue-type plasminogen activator; PAI-I, plasminogen activation inhibitor $I$. $(r=-0.551, P<0.01$, and $r=-0.583, P<0.01$, respectively), while PAI-1 correlated positively with CD4 cell count $(r=0.447, P<0.05)$. The correlations of these parameters at baseline, month 1, 2, and 3 are presented in Table 3.

Among the HIV patients undergoing ART, a progressive increase in CD4 cell count was observed from $192 \mu \mathrm{L} / \mathrm{mL}$ at baseline to $323 \mu \mathrm{L} / \mathrm{mL}$ after 3 months of therapy. In contrast, there was a significant drop in the CD4 count from $329 \mu \mathrm{L} / \mathrm{mL}$ at baseline to $310 \mu \mathrm{L} / \mathrm{mL}$ at the end of the third month among non-ARV patients. Figure 1 shows a reciprocal trend in CD4 $\mathrm{T}$ cell count between ARV and non-ARV subjects.

In ARV patients, D-dimer values dropped from $301.0 \mu \mathrm{L} / \mathrm{mL}$ at baseline to $172.0 \mu \mathrm{L} / \mathrm{mL}$ at month 2 , and then increased again to $226.0 \mu \mathrm{L} / \mathrm{mL}$ at the end of the third month. The reverse was seen in patients who were not on ART, as illustrated in Figure 2.

The median baseline value of PAI-1 at the beginning of therapy was $14.0 \mu \mathrm{g} / \mathrm{mL}$, which increased progressively to $18.2 \mu \mathrm{g} / \mathrm{mL}$ at the end of the third month. The baseline value of t-PA at the beginning of therapy was $5.15 \mu \mathrm{g} / \mathrm{mL}$. This value progressively declined to $1.10 \mu \mathrm{g} / \mathrm{mL}$ at the end of the first month. The value increased slightly to $1.45 \mu \mathrm{g} / \mathrm{mL}$ and $1.5 \mu \mathrm{g} / \mathrm{mL}$ at the end of the second and third months, respectively. The trend among the non-ARV patients was reciprocal in nature when compared to those on therapy, and is illustrated in Figure 3.

\section{Discussion}

The major finding from this preliminary START study is that there is interplay between t-PA, D-dimer, and PAI-1 resulting from the impact of ART. This impact is reciprocal in nature. It appears that HAART increases the CD4 T cell count while also promoting the release of plasminogen activator inhibitor, which suppresses the action of t-PA. This induces a hypofibrinolytic state, with a reduction in D-dimer values able to be observed by the end of the first month. By the second month, the PAI-1 level drops considerably, allowing the t-PA level to start rising. A further increase in PAI-1 level occurred at the end of the second month with t-PA activity remaining low, maintaining a hypofibrinolytic state in the first 2 months of treatment. As the t-PA values increased moderately from the second month, there was a corresponding increase in the D-dimer concentrations, but these remained within the normal range.

A positive correlation seems to exist, however, between t-PA and D-dimer, even though this was not statistically significant. A significant negative correlation exists 
Table 3 Correlation between measured parameters by antiretroviral therapy and duration of therapy

\begin{tabular}{|c|c|c|c|c|c|c|}
\hline Duration of therapy & Parameter & Age & CD4 & D-dimer & PAI-I & t-PA \\
\hline \multirow[t]{5}{*}{ Baseline } & Age & & -0.035 & -0.195 & 0.212 & $-0.458^{*}$ \\
\hline & CD4 & 0.189 & & $-0.519 * *$ & 0.184 & -0.035 \\
\hline & D-dimer & $-0.76 I^{* * *}$ & -0.114 & & 0.773 & 0.989 \\
\hline & PAI-I & -0.013 & 0.257 & -0.205 & & $-0.543^{* *}$ \\
\hline & $\mathrm{t}-\mathrm{PA}$ & 0.361 & 0.384 & -0.412 & 0.734 & \\
\hline \multirow[t]{5}{*}{ Month I } & Age & & 0.236 & -0.195 & 0.212 & $-0.458^{*}$ \\
\hline & CD4 & 0.01 & & $-0.519 *$ & 0.184 & -0.035 \\
\hline & D-dimer & -0.184 & $0.621^{* *}$ & & 0.069 & -0.003 \\
\hline & PAI-I & -0.174 & 0.27 & 0.288 & & $-0.543^{* *}$ \\
\hline & $\mathrm{t}-\mathrm{PA}$ & -0.354 & $-0.465^{*}$ & $-0.474^{*}$ & $-0.545^{* *}$ & \\
\hline \multirow[t]{5}{*}{ Month 2} & Age & & 0.125 & -0.262 & 0.097 & 0.391 \\
\hline & CD4 & 0.234 & & $-0.533^{*}$ & 0.277 & -0.258 \\
\hline & D-dimer & $-0.499 *$ & $-0.515^{*}$ & & -0.158 & -0.161 \\
\hline & PAI-I & -0.414 & 0.093 & $0.550 * *$ & & -0.312 \\
\hline & $\mathrm{t}-\mathrm{PA}$ & -0.106 & -0.439 & 0.26 & 0.035 & \\
\hline \multirow[t]{5}{*}{ Month 3} & Age & & 0.233 & -0.262 & 0.064 & 0.125 \\
\hline & CD4 & $0.723 * * *$ & & $-0.551 * *$ & 0.054 & $-0.583^{* *}$ \\
\hline & D-dimer & $-0.563 * *$ & -0.166 & & 0.381 & 0.162 \\
\hline & PAI-I & 0.094 & $0.447^{*}$ & 0.402 & & -0.342 \\
\hline & $\mathrm{t}-\mathrm{PA}$ & $-0.28 \mathrm{I}$ & -0.351 & 0.051 & 0.163 & \\
\hline
\end{tabular}

Notes: Within the duration of therapy, correlation values below the diagonal are for HIV-infected patients on ARV therapy, while correlation values above the diagonal are for HIV-infected patients not on ARV therapy $(\mathrm{N}=20)$. Significance levels: $* P<0.05$; $* * P<0.01$; $* * * P<0.00 \mathrm{I}$.

Abbreviations: ARV, acquired immunodeficiency syndrome-associated retrovirus; HIV, human immunodeficiency virus; t-PA, tissue-type plasminogen activator; PAI-I, plasminogen activation inhibitor $\mathrm{I}$.

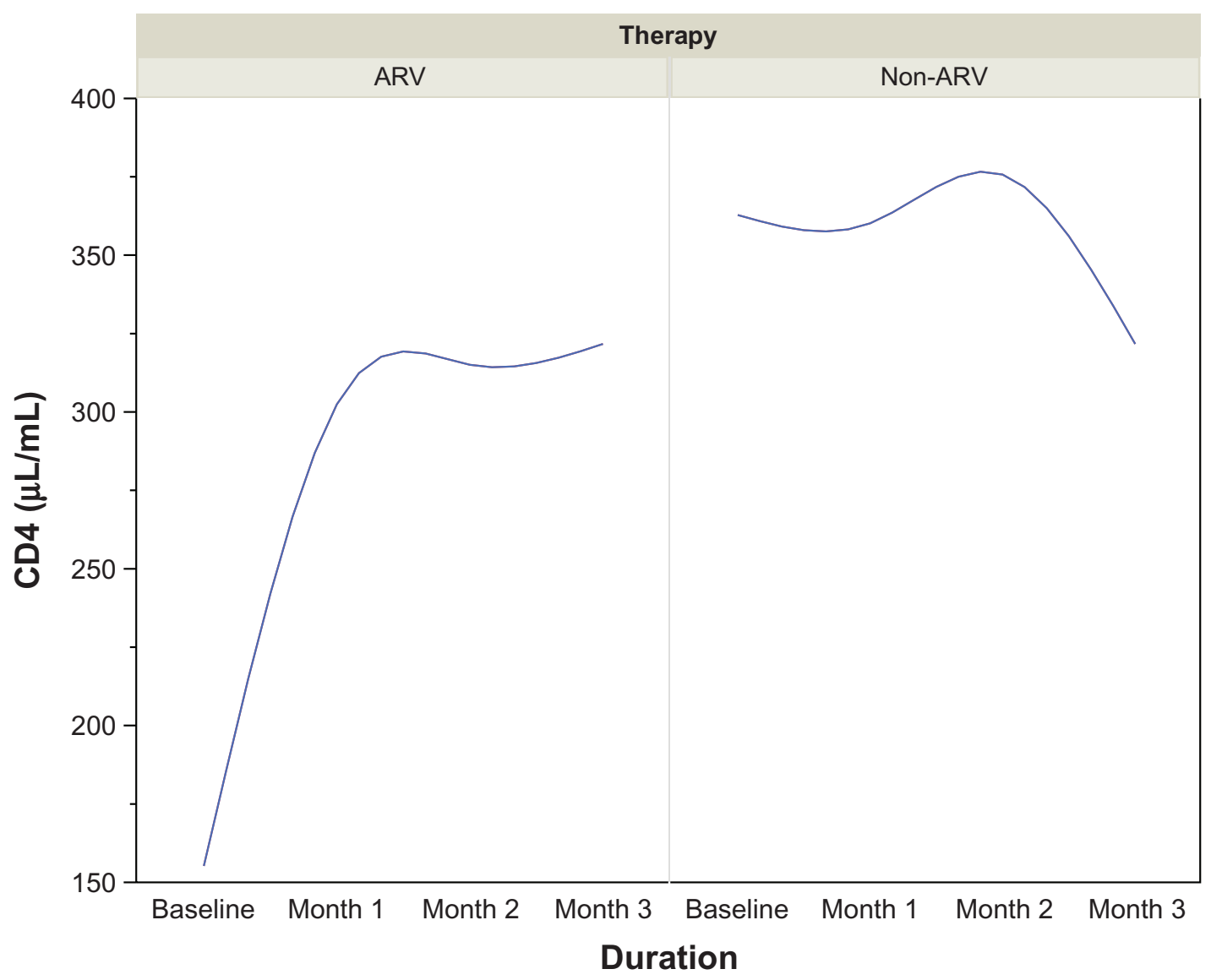

Figure I Trends in CD4 $(\mu \mathrm{L} / \mathrm{mL})$ in HIV-infected patients on ARV therapy by duration. Abbreviations: HIV, human immunodeficiency virus; ARV, AIDs-associated retrovirus. 


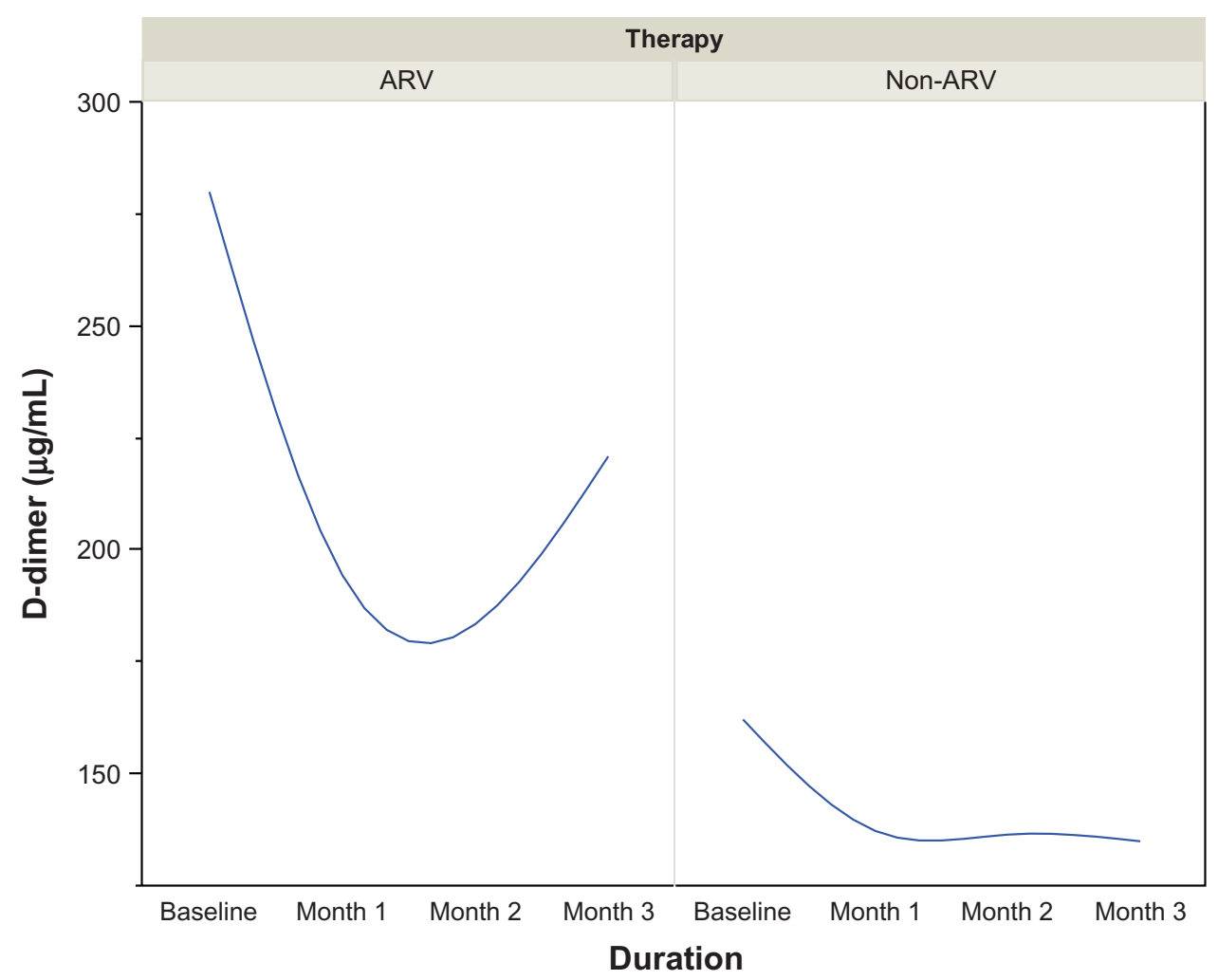

Figure 2 Trends in D-dimer $(\mu \mathrm{g} / \mathrm{mL})$ in HIV-infected patients on ARV therapy by duration.

Abbreviations: HIV, human immunodeficiency virus; ARV, AIDs-associated retrovirus.

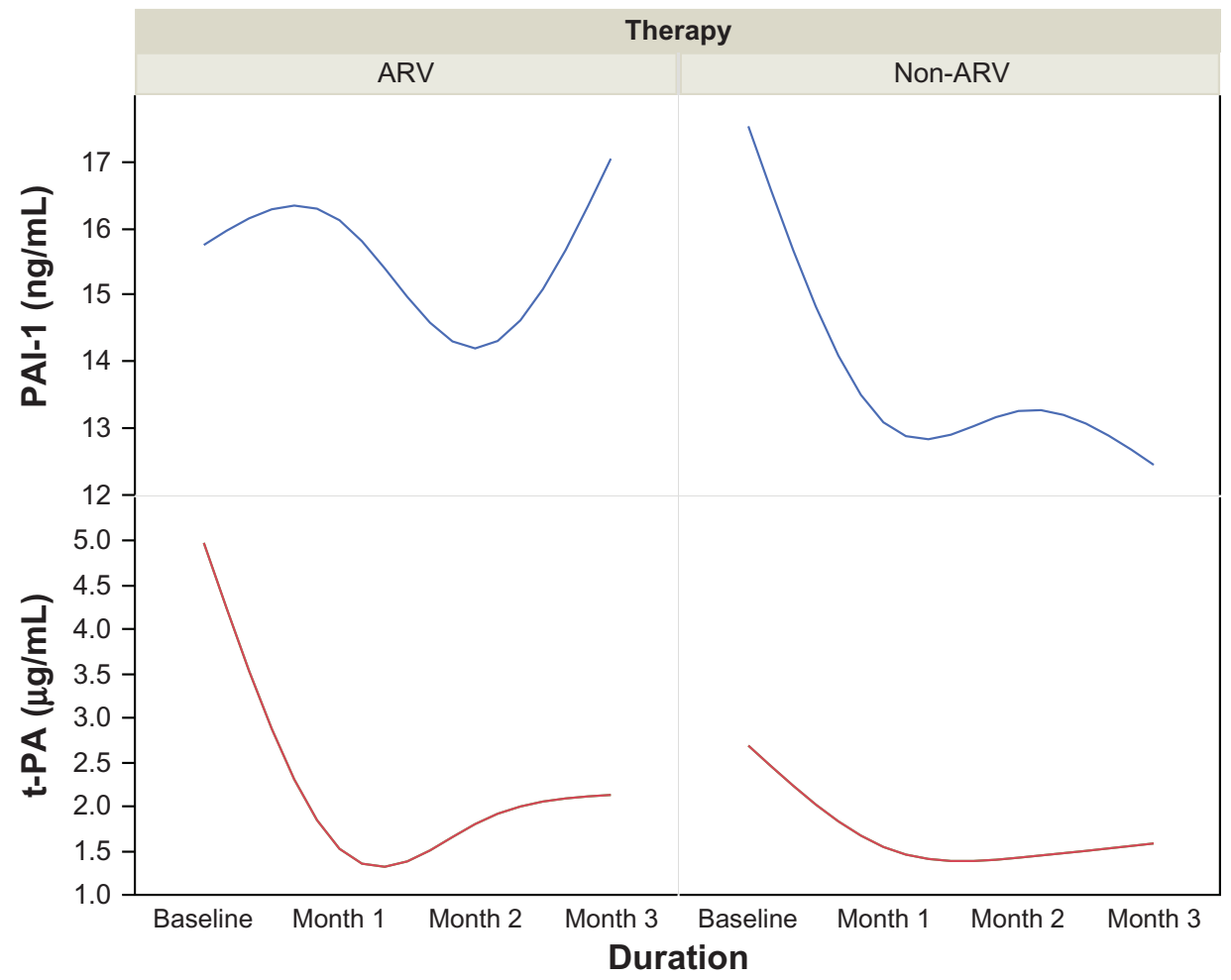

Figure 3 Trends in PAI-I $(\mu \mathrm{g} / \mathrm{mL})$ and t-PA $(\mu \mathrm{g} / \mathrm{mL})$ in HIV-infected patients on ARV therapy by duration.

Abbreviations: HIV, human immunodeficiency virus; ARV, AIDs-associated retrovirus; PAI-I, plasminogen activation inhibitor; t-PA, tissue-type plasminogen activator. 
between CD4 T cell count and D-dimer in HAART patients. It follows that with HAART therapy, the CD4 T cell count increases while t-PA value decreases. The hypofibrinolytic state observed in the current study is corroborated by earlier reports that ART induces a hypofibrinolytic state as a result of the increase in PAI-1, which is reported to be marker of atherothrombotic risk. ${ }^{14-16}$ Several other cases of thrombosis associated with protease inhibitors (PIs) containing HAART have been reported. ${ }^{17,18}$ The PIs containing HAART are believed to promote thrombosis through pleiotropic effects, including alterations in lipid, PAI-1, and fibrogen levels.

Crum-Cianflone et al reported that the progression of $\mathrm{HIV}$ is associated with $\mathrm{T}$ cell proliferation and activation, as well as high levels of circulating inflammatory markers, with immune activation persisting long after initiation of HAART rather than ART. ${ }^{19}$ The inflammatory responses caused by advanced HIV disease play a pivotal role in the pathogenesis of atherosclerosis inflammation, endothelial dysfunction, and impaired fibrinolysis, which may further contribute to the increased cardiovascular risk observed in the HIV-infected population. ${ }^{9-11}$ The pro-inflammatory state associated with HIV infection may also give rise to atherogenic lipid changes. The lipid profile in antiretroviral-naïve HIV-infected subjects is characterized by low total cholesterol, HDL cholesterol, and LDL cholesterol, as well as elevated triglyceride levels (mainly appearing as low density lipoprotein). ${ }^{12-15}$ Substantial evidence exists that HAART induces a hypofibrinolytic state in HIV-infected individuals, as reflected in increased plasma levels of plasminogen activator and homocystein, which are thought to be markers of atherothrombotic risk. ${ }^{14-16}$

In this study, a negative correlation was observed between CD4 T lymphocytes and D-dimer concentrations. The implication is that an increase in CD4 T lymphocytes will lead to a decrease in the D-dimer concentrations, and vice versa. This observation appears to agree with an earlier report by Crum-Cianflone et al, ${ }^{19}$ who found that venous thromboembolisms are associated with low CD4 cell counts. This appears to be a result of immune/inflammatory activation causing increased D-dimer concentrations, which induces a hypercoagulable state.

\section{Conclusion}

ART may play a major role in promoting arterial and venous thrombosis among HIV-infected persons as early as 3 months into the treatment. Prethrombotic assessment through measurement of fibrinolytic parameters should be introduced early in the course of ART.

\section{Disclosure}

The authors report no conflicts of interest in this work.

\section{References}

1. Murphy EL, Collier AC, Kalish LA, et al. Highly active anti-retroviral therapy decreases mortality and morbidity in patients with advanced HIV disease. Ann Intern Med. 2001;135(1):17-26.

2. Passalaris JD, Sepkowitz KA, Glesby MJ. Coronary artery disease and human immunodeficiency virus infection. Clin Infect Dis. 2000;31(3): 787-797.

3. Rhew DC, Bernal M, Aguilar D, Iloeje U, Goetz MB. Association between protease inhibitor rise and increased cardiovascular risk in patients infected with human immunodeficiency virus: a systematic review. Clin Infect Dis. 2003;37(7):959-972.

4. Gorog DA. Prognostic value of plasma fibrinolysis activation markers in cardiovascular diseases. J Am Coll Cardiol. 2010;55(24): 2701-2709.

5. Nordenham A, Wiman B. Tissue plasminogen activator (tPA) antigen in plasma: correlation with different tPA/inhibitor complexes. Scand J Clin Lab Invest. 1998;58(6):475-483.

6. Wiman B. Predictive value of fibrinolytic factors in coronary heart disease. Scand J Clin Lab Invest Suppl. 1999;230:23-31.

7. May M, Lawlor DA, Patel R, Rumley A, Lowe G, Ebrahim S. Association of von Willebrand factor, fibrin D-dimer and tissue plasminogen activator with incident coronary heart disease: British Women's Heart and Health cohort study. Eur J Cardiovasc Prev Rehabil. 2007;14(5):638-645.

8. Crum NF, Riffenburgh RH, Wegner S, et al. Comparison of causes of death and mortality rates among HIV-infected persons: analysis of pre-, early, and late HAART (highly active antiretroviral therapy) eras. J Aquire Immune Defic Syndr. 2006;41(2):194-200.

9. Valdez H, Connick E, Smith KY, et al. Limited immune restoration after 3 years' suppression of HIV-1 replication in patients with moderately advanced disease. AIDS. 2002;16(14):1859-1866.

10. Ross R. Atherosclerosis - an inflammatory disease. N Engl J Med. 1999;340(2):115-126.

11. Hansson CK, Libby P, Schönbeck U, Yan ZQ. Innate and adaptive immunity in the pathogenesis of atherosclerosis. Circ Res. 2002;91(4):281-291.

12. Nguemaim NF, Mbuagbaw J, Nkoa T, et al. Changes in lipid profiles in two groups of HIV-1 infected patients in Cameroon on two treatment regimens with either Efavirenz or Nevirapine, in association with reverse transcriptase inhibitors. J Med Sci. 2010;10(2):25-33.

13. Nguemain NF, Mbuagbaw J, Nkoa T, et al. Serum lipid profile in highly active antiretroviral therapy-naïve-HIV infected patients in Cameroon: a case-control study. HIV Med. 2010;11(6):353-359.

14. Beerasconi E, Uhr M, Magenta L, Ranno A, Telenti A, Swiss HIV Cohort Study. Homocysteinaemia in HIV-infected patients treated with highly active antiretroviral therapy. AIDS. 2001;15(8): 1081-1082.

15. Koppel K, Bratt G, Schulman S, Bylund H, Sandström E. Hypofibrinolytic state in HIV infected patients treated with protease inhibitor-containing highly active antiretroviral therapy. J Aquir Immune Defic Syndr. 2002; 29(5):441-449.

16. Folsom AR. Fibrinolytic factors and atherothrombotic events: epidemiological evidence. Ann Med. 2000;32 Suppl 1:85-91.

17. George SL, Swindells S, Knudson R, Stapleton JT. Unexplained thrombosis in HIV-infected patients receiving protease inhibitors: report of seven cases. Am J Med. 1999;107(6):624-630. 
18. Jacobson MC, Dezube BJ, Aboulafia DM. Thrombotic complications in patients infected with HIV in the era of highly active antiretroviral therapy: a case series. Clin Infect Dis. 2004;39(8): $1214-1222$.
19. Crum-Cianflone NF, Weekes J, Bavaro M. Review: thromboses among HIV-infected patients during the highly active antiretroviral therapy era. AIDS Patient Care STDS. 2008;22(10):771-778.

\section{Publish your work in this journal}

HIV/AIDS - Research and Palliative Care is an international, peerreviewed open-access journal focusing on advances in research in HIV, its clinical progression and management options including antiviral treatment, palliative care and public healthcare policies to control viral spread. The journal welcomes original research, basic science, clinical \& epidemiological studies, reviews \& evaluations, expert opinion \& commentary, case reports \& extended reports. The manuscript management system is completely online and includes a very quick and fair peer-review system. Visit http://www.dovepress.com/ testimonials.php to read real quotes from published authors.

Submit your manuscript here: http://www.dovepress.com/hivaids---research-and-palliative-care-journal 